\title{
Regions Respond to Catastrophes
}

Thomas D. Kirsch, MD, MPH; Jeff Schlegelmilch, MPH, MBA; Kandra Strauss-Riggs, MPH; Thomas Chandler, PhD; Irwin Redlener, MD

A s Hurricane Sandy struck the New York region on October 31, 2012, the health system faced unprecedented challenges, ranging from closed and evacuated hospitals to the loss of power and depleted fuel supplies for millions of residents. Although the storm caused more than $\$ 71$ billion in damages, with thousands of vulnerable patients surging into hospitals and special needs shelters, few lives were lost directly from the storm. However, public health agencies, health care partners, and community-based organizations were forced both to respond to the event and adapt to the loss of health care facilities with existing and ad hoc response systems. ${ }^{1}$

In the biomedical literature, the concept of health care "surge capacity" became prominent in 2002, after the 9-11 terrorist attacks, and received increased emphasis after Hurricane Katrina destroyed the New Orleans health care system. The Agency for Healthcare Research and Quality defines surge capacity as "a health care system's ability to expand quickly beyond normal services to meet an increased demand for medical care in the event of bioterrorism or other large-scale public health emergencies." ${ }^{2}$ Yet, as noted by Jenkins et $\mathrm{al}^{3}$, a longstanding challenge in the field is that mass casualty planning is not currently designed to withstand the resulting patient surge during such incidents, and that trauma "surges" lead to excess deaths.

In large-scale disasters that include but are not limited to detonation of an improvised nuclear device, a major earthquake, or another large hurricane striking a major US city, we will simultaneously lose health care system capacity with damage to facilities while needing to care for a surge of injured and ill people seeking care. This cannot be accomplished by a single or few facilities, but requires a region-wide plan.

\section{PRIOR AND CURRENT NATIONAL ACTIVITIES}

In the United States, several initiatives have been aimed at improving our ability to respond to a large surge event. There has been some, albeit limited, intra-sector and inter-sector surge planning across the civilian, military, and private partners. The most consistent strategic impetus toward greater planning has been through the Hospital Preparedness Program
(HPP) grant program (currently administered through the Department of Health and Human Services' Assistant Secretary for Preparedness and Response). This funding is provided through state and local governments to support regional health care readiness. Between 2002 and 2015, the HPP has awarded over $\$ 5$ billion to states, selected cities, and the US territories to form health care coalitions with hospitals and other providers. A portion of the funds are distributed to health care providers to improve their emergency preparedness and to encourage collaboration and mutual planning. The program's budget has been reduced by more than $50 \%$ over 13 years, with more cuts requested in the proposed White House budget. ${ }^{4}$ Additionally, since HPP funds flow through states and local jurisdictions, federal facilities such as US Department of Veterans Affairs and Department of Defense hospitals are often not included in the coalitions actually receiving funds.,

After the widespread impact of Hurricane Sandy on health care facilities such as long-term care facilities, dialysis centers, outpatient surgical centers, and others, the Centers for Medicare and Medicaid Services (CMS) published their final rule for health care emergency preparedness in 2016. This regulation provides a national baseline of preparedness for most health care providers. This rule requires relevant facilities to have (1) an emergency plan, (2) policies and procedures, (3) a communications plan, and (3) a training and testing program. ${ }^{7}$ While this creates an important floor for preparedness among all institutions receiving reimbursement for services from CMS, it merely codifies standards already put in place by the HPP and the Joint Commission and other preparedness standards that most hospitals already follow. ${ }^{8}$

The National Disaster Medical System (NDMS) was also established and serves as a federally coordinated partnership of the Departments of Health and Human Services, Homeland Security, Defense, and Veterans Affairs. Its purpose is to "support State, local, Tribal and Territorial authorities following disasters and emergencies by supplementing health and medical systems and response capabilities. NDMS would also support the military and Veterans Health Administration health care systems in caring for combat casualties, should requirements exceed their capacity." 
Additional funding through funding streams from the US Department of Homeland Security such as the Urban Areas Security Initiative and the state Homeland Security Grant Program, as well as funding from the US Centers for Disease Control and Prevention (CDC) for bioterrorism and infectious disease preparedness provide some resources to augment core planning efforts, but these funds have also been reduced and are spread across many mission areas.,

The federal government also has the capacity to supplement state and local health response in the event that aid is requested and a federal Stafford Act disaster is declared. These Emergency Support Function 8 assets are loosely modeled on Department of Defense medical capabilities and include Federal Medical Stations, Disaster Medical Assistance Teams, Disaster Mortuary Assistance Teams, Veterinary Medical Assistance Teams, National Medical Response Teams, deployable US Public Health Service teams, the Laboratory Response Network, the CDC Strategic National Stockpile, and Federal Emergency Management Agency reimbursement for acute care hospital care provided during a disaster.

While these assets are available within days of an event, they are not immediately available, remain limited in scope, and are intended to provide temporary support to communities. They are not designed to assist with region-wide evacuations or transfers that would impact health care facilities in a large regional event.

The Medical Reserve Corps (MRC), with 200,000 volunteers throughout the country, is an important capability in many localities. While their volunteers are impressively engaged in community preparedness activities, the MRC would benefit from additional funding to support higher level training and increased regional coordination.

\section{DISCUSSION}

The American health care system is not ready for a large disaster event with hundreds let alone thousands or even tens of thousands of casualties. Such a catastrophic event, whether a natural disaster or terrorist event, will undoubtedly cause damage to some hospitals and other health care facilities, while simultaneously increasing the number of injured seeking care. The combined loss of capacity and increased need could be devastating without proper planning. We must create regional health care systems that allow for partial "controlled failure" of some of the facilities but are still able to surge to provide optimum care for the injured and sick. Deploying assets from the rest of the nation cannot meet the "golden hour" needs of the critically sick and injured.

Despite prior efforts, many constraints still limit the health care system's ability to provide care in catastrophic disaster events. The greatest difficulty is that most essential components of the American health care system operate within the private sector, even though these functions are vital elements of the critical infrastructure necessary for disaster response. Other aspects of critical infrastructure are either publicly owned or heavily regulated to require preparedness and mitigation. Hospitals have been required to have disaster planning for many years, and the aforementioned CMS Emergency Preparedness Rule now requires 17 other types of health care providers from nursing homes to dialysis centers to plan and train for disasters. However, hospitals and long-term care facilities survive on a thin profit. The American Hospital Association reported that in 2014, $30 \%$ of all hospitals had a negative operating margin and that the average operating margin was just $6.4 \% .{ }^{10}$ The cost of preparedness and stockpiling adds further stress to these thin margins. Private facilities also compete with one another in the same regional market, which would require coordinated planning and response efforts. They have economic incentive to compete, not to cooperate.

Budget cuts for health and public health preparedness also have a great impact beyond the disaster-specific grants described above. The American Hospital Association states that if the Affordable Care Act is repealed, "Losses of this magnitude cannot be sustained and will adversely impact patients' access to care, decimate hospitals' and health systems' ability to provide services...."11 In addition to this reduction, the current budget proposes even greater reductions in federal spending for health care preparedness. ${ }^{4}$

In conclusion, a more comprehensive approach to health care preparedness is required. The piecemeal approach and shortterm budgeting will not create the kind of cross-sector, health care response infrastructure that is required to meet $21 \mathrm{st}$ century challenges. A true strategy for improving regional health care surge response requires, among other things:

- Funding and leadership to establish a stronger evidence base for health care surge events, including modeling to predict impacts on and needs for post-disaster health services.

- Operational research to identify best practices in communication, coordination, and service delivery.

- Increased and stabilized funding for the health care preparedness programs with stronger emphasis on integration with Department of Defense and Veterans Affairs (including but not limited to NDMS).

- Stronger incentives for private sector investment in preparedness and regional coordination.

Continuing discussions among the disaster response community following Superstorm Sandy emphasized the need for more extensive and effective regional surge capacity planning as an essential component of preparing for future natural and human-caused mass casualty incidents likely to be more severe and unpredictable. 


\section{About the Authors}

National Center for Disaster Medicine and Public Health, Uniformed Services University, Bethesda, Maryland (Dr Kirsch and Ms Strauss-Riggs); National Center for Disaster Preparedness (NCDP) at Columbia University's Earth Institute, New York, New York (Mr Schlegelmilch); NCDP and Teachers College, Columbia University, New York, New York (Dr Chandler); NCDP and Department of Health Policy and Management, Mailman School of Public Health, Columbia University, and Children's Health Fund, New York, New York (Dr Redlener).

\section{REFERENCES}

1. Chandler T, Abramson DM, Panigrahi B, et al. Crisis decisionmaking during Hurricane Sandy: an analysis of established and emergent disaster response behaviors in the New York metro area. Disaster Med Public Health Prep. 2016;10(3):436-442. https://doi.org/10.1017/dmp.2016.68.

2. Agency for Health care Research and Quality. Bioterrorism and Health System Preparedness: Issue Briefs. AHRQ website. https://archive.ahrq. gov/news/ulp/btbriefs/. Published 2006. Accessed July 20, 2017.

3. Jenkins PC, Richardson CR, Norton EC, et al. Trauma surge index: advancing the measurement of trauma surges and their influence on mortality. J Am Coll Surg. 2015;221(3):729-738.e1. https:/doi.org/ 10.1016/j.jamcollsurg.2015.05.016.

4. White House. Budget for the U.S. Government. A New Foundation for America Greatness. https://www.whitehouse.gov/sites/whitehouse.gov/ files/omb/budget/fy2018/budget.pdf. Accessed July 30, 2017.
5. Schlegelmilch J, Petkova E, Redlener I. Disaster prepared: how federal funding in the USA supports health system and public health readiness. J Bus Continuity Emerg Plann. 2015;9(2):112-118.

6. Watson C, Watson M, Kirk Sell T. Federal funding for health security in FY2018 [published online June 27, 2017]. Health Secur. doi: 10.1089/hs. 2017.0047.

7. Centers for Medicare \& Medicaid Services. Emergency Preparedness Rule. CMS.gov website. https://www.cms.gov/Medicare/Provider-Enrollmentand-Certification/SurveyCertEmergPrep/Emergency-Prep-Rule.html. Last updated June 20, 2017. Accessed July 20, 2017.

8. YNHHS-CEPDR. CMS Emergency Preparedness Final Rule Crosswalk Updated. New Haven, CT: Yale New Haven Health System Center for Emergency Preparedness and Disaster Response; 2017.

9. US Department of Health and Human Services, Office of the Assistant Secretary for Preparedness and Response. National Disaster Medical System. Public Health Emergency website. https://www.phe.gov/Preparedness/ responders/ndms/Pages/default.aspx. Last updated April 21, 2017. Accessed July 20, 2017.

10. American Hospital Association. Trendwatch Chartbook 2016 - Trends Affecting Hospitals and Health Systems. AHA website. http://www.aha. org/research/reports/tw/chartbook/index.shtml. Published 2016. Accessed July 20, 2017.

11. Federation of American Hospitals and American Hospital Association. Estimating the impact of repealing the Affordable Care Act on hospitals. http://www.aha.org/content/16/impact-repeal-aca-report.pdf. Published 2016. Accessed July 17, 2016.

\section{Cover Image:}

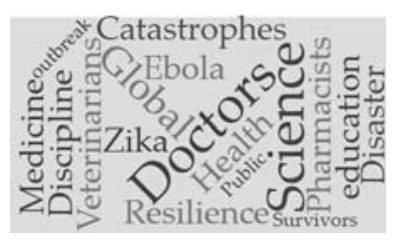

Components of a disaster 